\title{
Re-inventing the production of adhesive from Cassava starch as a career opportunity in chemistry education
}

\author{
Buba A. Aliyu ${ }^{1}$, Kabiru Baraya Aliyu ${ }^{2}$ \\ ${ }^{1}$ Moddibo Adama University of Technology, Yola, Nigeria \\ ${ }^{2}$ Chemistry Department, College of Education, Azare-Bauchi State, Nigeria
}

\begin{abstract}
The present study is aimed at investigating the properties of Cassava starch for the production of adhesives as a career opportunity in chemistry education. Method of starch extraction, characterization and adhesive production for quality assessment was performed. The results showed that adhesives produced with sodium hydroxide as a gelatinization enhancer has a maximum drying time of 8.60 minutes and had a stronger bond. The work concludes that the adhesive produced is of good quality and can lead to re-inventing chemistry education as a career opportunity. However, the Cassava adhesive met the basic requirement for adhesive use and application. At the end recommendations were made, among others increase employment opportunities, also diversify the economic base of farmers and there is need for reorientation and attitudinal change towards entrepreneurial job.
\end{abstract}

Keywords: Cassava; starch; chemistry education

\section{INTRODUCTION}

Throughout most of the 8,200 year history of adhesives, natural sources have dominated the adhesive chemist's stockpile of raw material (Robert, 2002). Not until well into the $20^{\text {th }}$ Century did synthetic raw material sources become important part of the adhesive formulator's bag of tricks, as reported by (Robert, 2002).

Adhesive materials have been used successfully in a variety of applications for centuries. Today adhesives are more important than ever in our daily lives and their usefulness is increasing rapidly. People now routinely trust their fortunes and their lives to adhesively bonded structure and rarely think about it, but the subject of adhesives and adhesive bonding is of great importance to researchers. Materials are generally defined as adhesives by what they do. Almost any organic polymer and even many inorganic materials can function as adhesives in some situation. However, whether they are organic or inorganic, all adhesives share common traits in performing their functions; An adhesive, by surface attachment only ,transfers and distributes mechanical loads among the components of an assembly, at some time in the course of the bond formation, the adhesive must be liquid or behave as a liquid in order to wet the adherents, adhesive carries some continuous ,low and often variable load throughout its life, an adhesive must work with the other components of 
the assembly to provides a durable product that is resistant to degradation by elements of the environment in which it will be used (James' 1997).

There are two main broad categories of adhesives; natural and synthetic. Natural adhesives includes, animal glues, casein glues, natural gums and resins, sodium silicates and vegetable glues. Vegetable glues are starch-based and are made from starches and dextrins. Starch has several advantages as a raw material in the production of adhesives including; renewability, biodegradability, abundance, cheapness and stability in price. Starch-adhesives can be applied at ambient or moderately low temperature, are usually re-wetable, and have little or no odour or taste at all, (Mehdi et al., 2010).

A recent study Sharma (2011), adhesive may be regarded as a substance or material capable of uniting or bonding two other materials together by adhering strongly to the surface of both. The bond formed, should, however, be strong between the two surfaces; otherwise there would be no effective bonding (Sharma, 2011).

A liquid adhesive is suitable for a particular surface, if it is capable of wetting that particular surface. The wettability of a particular adhesive depends upon viscosity, surface tension and a number of various other factors of the liquid adhesive .The attraction between the liquid adhesive and the surface are greatest when the interfacial tension between the two is smallest. A porous surface has numerous capillaries, while a smooth surface is free from such capillaries. On this basis, materials such as leather, paper, wood and ceramics are called porous (Akpan, 2012).

According to Darkwa, (2003), Cassava (manihot exculenta) is a perennial vegetative propagated shrub mainly grown for its edible roots. The roots can be processed into major products as chips, flour, gari, starch, etc. The purified starch extracted from the minor root is commonly referred to in the trade, as "cassava flour "but cassava starch and cassava flour are the same. However some producers refer to the ground dried whole cassava root as "cassava flour" but it is more properly cassava meal as it contains a considerable amount of fiber and root peel. The requirements of quality, quantity and end use of the cassava starch determine the processing of technique to be employed in the manufacture. The application of starch in food industry is widely known but other application in other industries is now coming up.

According to Adeyemo (2010), skill is thought of as a quality of performance which does not depend solely upon person fundamental inmate capacities but must be developed through training, practice and experience. In science education particularly chemistry, student acquire skills during their course of study and develop them as a career opportunity as a result of some challenges facing the society. In chemistry education, an entrepreneur needs some skills for simple and easy production of chemical product. The process skills in chemistry help the entrepreneur in no small measure to produce adhesive from cassava starch.

\section{1. The Starch}

In a recent research conducted by Joel (2010) explained that, Starch is the principal energy storage polysaccharide in photosynthetic plant. Most starches have two structurally different forms -amylose, a linear polymer having degrees of polymerization between 100 and 6,000 and a high concentration of amylopectin, a highly branched fraction. Branches in amylopectin are 12 to 15 glucose residues in length and occur at every sixth to twelfth backbone residue. Starch is the major component of flour, potatoes, rice, beans and corns. It is a mixture of two different polysaccharides: amylose (about $20 \%$ ) and amylopectin (about $80 \%$ ).Amylose is composed of unbranched chain of D-glucose units joined by $\alpha-1,4-$ glycosidic linkages.Amylopectin is a branched polysaccharide. Like amylose it is composed 
of chains of D-glucose units joined by $\alpha$-1,4-glycosidic linkages. Unlike amylose, however, amylopectin also contains $\alpha$ - 1,6-glycosidic linkages (Paula, 2011).

\section{MATERIALS AND METHOD}

The following materials are required for the research; Fresh Cassava roots, Cassava Starch, sodium hydroxide, disodium Tetraborax, distilled water, centrifuge tube, butanol, amyl alcohol, water bath ,methanol, microscope, beakers, Thermometers, Oven, $\mathrm{p}^{\mathrm{H}}$ Meter, Aluminium foil, porcelain crucible, Table, sand paper etc. The Analar grade chemicals were used.

\section{1. Collection and Identification of Cassava roots}

Cassava roots were obtained in a local farm settlement by the researcher in Ningi, Bauchi state, Nigeria and were identified in the presence of the researcher at the Biological science department college of education, Azare.

\section{2. Production of Starch}

A starch from Cassava was produced primarily by the wet milling of fresh Cassava roots. Extraction of starch from fresh Cassava roots was performed following the steps outlined in Figure 1. The extraction of starch was based on the method of Akpa (2012).

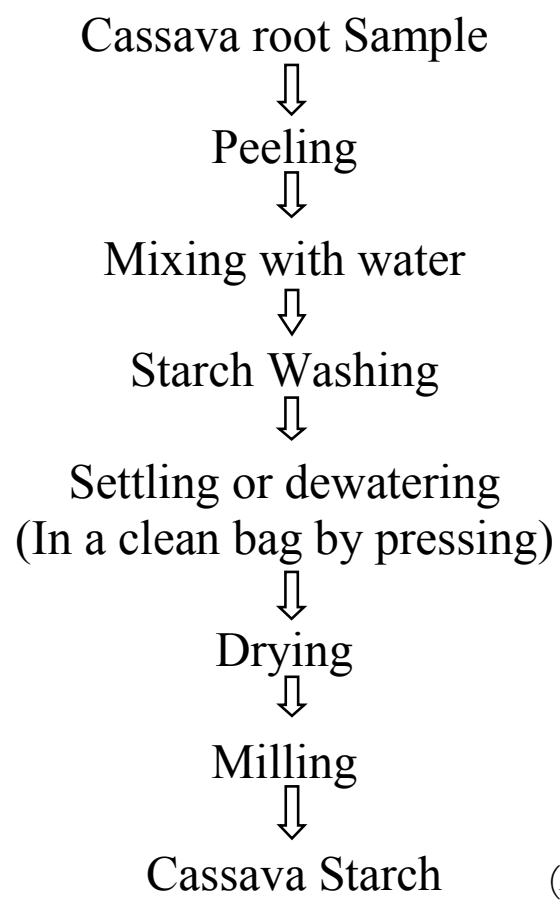

(Akpa, 2012)

Figure 1. Flow chart for the production of Cassava starch. 


\section{3. Production of Adhesive from Cassava Starch}

The adhesive was prepared by using the following procedure presented in Figure 2.

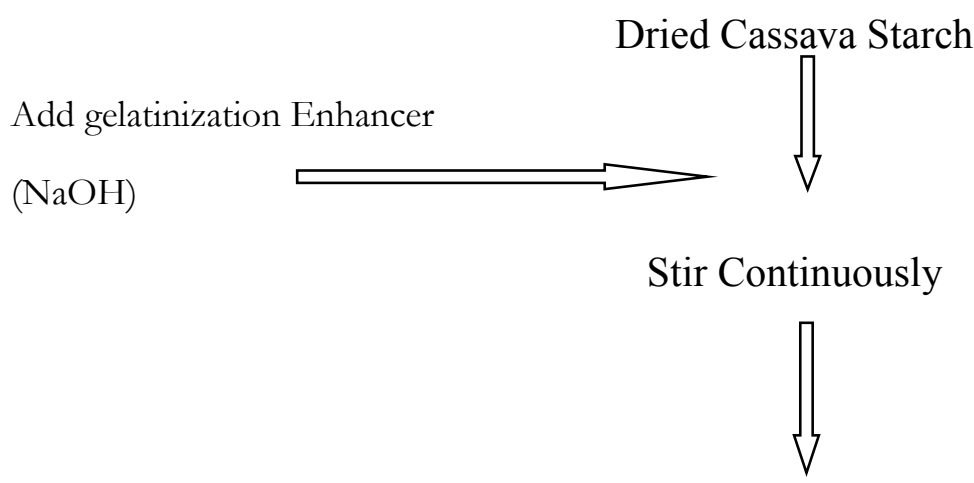

Heat in a heating mantle at desire temperature

Add viscosity Enhancer (Borax)

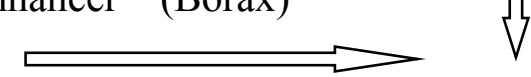

Stir continuously until the mixture become sticky

$$
\rrbracket
$$

Allow the product (Adhesive) to cool

(Source - Akpa, 2012)

Figure 2. Flow chart for the preparation of Adhesive

\section{ANALYTICAL PROPERTIES OF CASSAVA STARCH}

\section{1. Determination of moisture content of starch}

Starch Sample (5.0 g) was weighed into a porcelain dish and evaporated to dryness on a water bath. The porcelain containing Starch Sample was then transferred into an oven and maintained at $105^{\circ} \mathrm{C}$ for an hour, after which the sample was allowed to cooled and then reweighed. Heating and cooling is done till a constant weight was obtained. The difference between the initial weighed of starch and the final weighed of starch gives the moisture content of the starch (Darkwa, 2003).

\section{2. Determination of ash content}

Starch sample $(2.0 \mathrm{~g})$ was placed into a porcelain crucible and transfer into a preheated muffle furnace set at $900{ }^{\circ} \mathrm{C}$. The furnace was left on for one hour after which the crucible and its content were transferred to desiccators and allowed to be cool. The crucible and 
content were re-weighted and recorded. The \% ash content (dry basis) is given by the equation below (Aloko, 2007).

$$
\% \text { ash content }=\frac{W_{0}-W_{a s h}(\%)}{W_{0}}
$$

where;

$\mathrm{W}_{\mathrm{o}}$ is the dry weight of sample

$\mathrm{W}_{\text {ash }}$ is the constant weight after final drying

\section{3. Determination of Amylose/Amylopectin Ratio}

The study adopted by Muazu et al., (2011) was used; Each of the starch sample ( $2 \mathrm{~g}$ ) was suspended in $50 \mathrm{ml}$ distilled water. A 1:9 (v/v) butanol: water mixture was added with continuous stirring and heating to boiling. Butyl and amyl alcohol $(1: 1) \mathrm{v} / \mathrm{v}$ was added to the boiling suspension which was allowed to be cool in a water bath. The supernatant liquor was decanted and the microcrystalline precipitate formed was washed repeatedly with butanol saturated with water dried in an oven and weighed. The procedure was repeated twice and the mean value taken as the ratio of amylose. The supernatant was precipitated with excess methanol and the precipitate dried in an oven and weighed to determine the ratio of amylopectin.

\section{4. Solubility Test of Starch}

Starch sample $(1.0 \mathrm{~g})$ was weighed and poured into a beaker containing $1 \mathrm{ml}, 2 \mathrm{ml} 10$ $\mathrm{ml}, 1.0 \mathrm{~L}$ and $10 \mathrm{~L}$ distilled water at $25^{\circ} \mathrm{C}$ followed by stirring to observe the solubility. The same procedure was repeated using $95 \%$ alcohol as a solvent (Muazu et al., 2011).

\section{5. Determination of $P$ for Starch Sample}

Starch Sample $(5.0 \mathrm{~g}$ ) was weighted into $15 \mathrm{ml}$ of distilled water and mixed properly. The mixture was poured into boiling distilled water to make up $100 \mathrm{ml}$ of slurry. The slurry was allowed to cool. Using a $\mathrm{pH}$ Meter, the $\mathrm{pH}$ of the slurry was measured. The determination was performed in triplicate and the mean was considered as the $\mathrm{pH}$ of starch.

\section{PRESENTATION OF RESULTS}

Table 1. Analytical Properties of Cassava Starch.

\begin{tabular}{|c|c|c|c|c|c|c|}
\hline $\begin{array}{c}\text { Properties } \\
\text { Source }\end{array}$ & $\begin{array}{c}\text { Moisture } \\
\text { content } \\
(\%)\end{array}$ & $\begin{array}{c}\text { Ash content } \\
(\%)\end{array}$ & $\begin{array}{c}\text { Amylose } \\
(\%)\end{array}$ & $\begin{array}{c}\text { Amylopectin } \\
(\%)\end{array}$ & Solubility & $\mathrm{pH}$ \\
\hline $\begin{array}{c}\text { Cassava } \\
\text { starch }\end{array}$ & $5.76 \pm 0.28$ & $0.26 \pm 0.00$ & $22.95 \pm 0.80$ & $77.05 \pm 0.80$ & Insoluble & 5.4 \\
\hline
\end{tabular}


Table 2. Production of Adhesives from Cassava Starch.

\begin{tabular}{|c|c|c|c|c|c|c|c|}
\hline Source & $\begin{array}{c}\text { Weight } \\
\text { of starch } \\
(\mathrm{g})\end{array}$ & $\begin{array}{c}\text { Volume } \\
\text { of } \\
\text { distilled } \\
\text { water } \\
\left(\mathrm{cm}^{3}\right)\end{array}$ & $\begin{array}{c}\text { Volume } \\
\text { of } 0.1 \mathrm{M} \\
\mathrm{NaOH} \\
\left(\mathrm{cm}^{3}\right)\end{array}$ & $\begin{array}{c}\text { Quantity } \\
\text { of Borax } \\
\text { used }(\mathrm{g})\end{array}$ & $\begin{array}{c}\text { Quantity } \\
\text { of } \\
\text { Adhesive } \\
\text { produced } \\
\left(\mathrm{cm}^{3}\right)\end{array}$ & $\begin{array}{c}\text { Density } \\
\text { of the } \\
\text { Adhesive } \\
\left(\mathrm{g} / \mathrm{cm}^{3}\right)\end{array}$ & $\mathrm{pH}$ \\
\hline $\begin{array}{c}\text { Cassava } \\
\text { Starch }\end{array}$ & 5.0 & 50 & 50 & 0.2 & 100 & 1.025 & 11.80 \\
\hline
\end{tabular}

Table 3. Stabilization of Adhesives from Cassava starch.

\begin{tabular}{|c|c|c|}
\hline $\begin{array}{c}\text { Volume of starch } \\
(\mathrm{ml})\end{array}$ & $\begin{array}{c}\text { Quantity of Borax } \\
(\mathrm{g})\end{array}$ & $\begin{array}{c}\text { Temperature } \\
\left({ }^{\circ} \mathrm{C}\right)\end{array}$ \\
\hline 50 & 0.200 & 80 \\
\hline 50 & 0.180 & 75 \\
\hline 50 & 0.160 & 70 \\
\hline 50 & 0.140 & 65 \\
\hline
\end{tabular}

\section{DISCUSSION OF RESULTS}

The chemical composition of the Cassava starch is shown in Table 1. The purity of the starches was reasonably moderate. The moisture content $(5.76 \%)$ which falls within the moisture level (5\% to $20 \%$ ) as recommended for commercial starches (Soni et al.,1993) and below the maximum value (13\%) prescribed for safe storage in most starch producing countries. Climatic factors in addition to the process and the extend of drying influence as well as the moisture content of the starches (Oluwaseyi et al., 2012). High moisture content could encourage growth of microorganisms and leads to poor flow of the granules (Oduola et al., 2013).

The ash content of Cassava starch is 0.26 and fall within the limit $(0.5 \%)$ recommended for grade A industrial starches (Oluwaseyi et al.,2012).High ash content could be attributed to the presence of phosphate groups in starches (Hoover, 2001).

The amylose and amylopectin content of a given starch is an important factor that determines its characteristics and those of the adhesive derived from it. The higher the amylopectin contents, the better the starch for adhesive formulation. Since the data obtained compared favourably with literature values, it can be concluded that adhesives that could be manufactured from these materials would be f a very high standard. The Amylose content in Cassava starch $(22.95 \%)$ can compete favourably with the commercial starches. This is in agreement with the work of (Moorthy et al., 2002, Angraini et al., 2009; Visser et al., 1997). The amount of Amylose and Amylopectin found in starches depends on the source of the starch (Masumbu et al., 2002). 
The amylose and amylopectin ratio of this study falls under the specified limit of amylose and amylopectin ratio (Amylose 15-25 and amylopectin 75-85), as reported by (Muazu et al., 2011). Amylopectin ,being longer and more branched, imparts higher viscosity and thus making starch-based adhesives more viscous and tackier (Masumbu et al.,2002).

The solubility also provided the evidence of starch chains and water molecules interaction. In the study, Cassava starch is insoluble in water and at $95 \%$ alcohol. The $\mathrm{pH}$ at $25^{\circ} \mathrm{C}$, the values show that Cassava starch is acidic as observed from the analysis. In Figure 3 , as the mass of Borax increase so also the temperature increases.

\section{1. The Effect of Temperature on the Quantity of Borax}

A plot of the temperature and the quantity of borax is shown in Figure 3.The optimum temperature $\left(80^{\circ} \mathrm{C}\right)$ and borax requirements for stable adhesive with reduced retro gradation were determined from the curve.

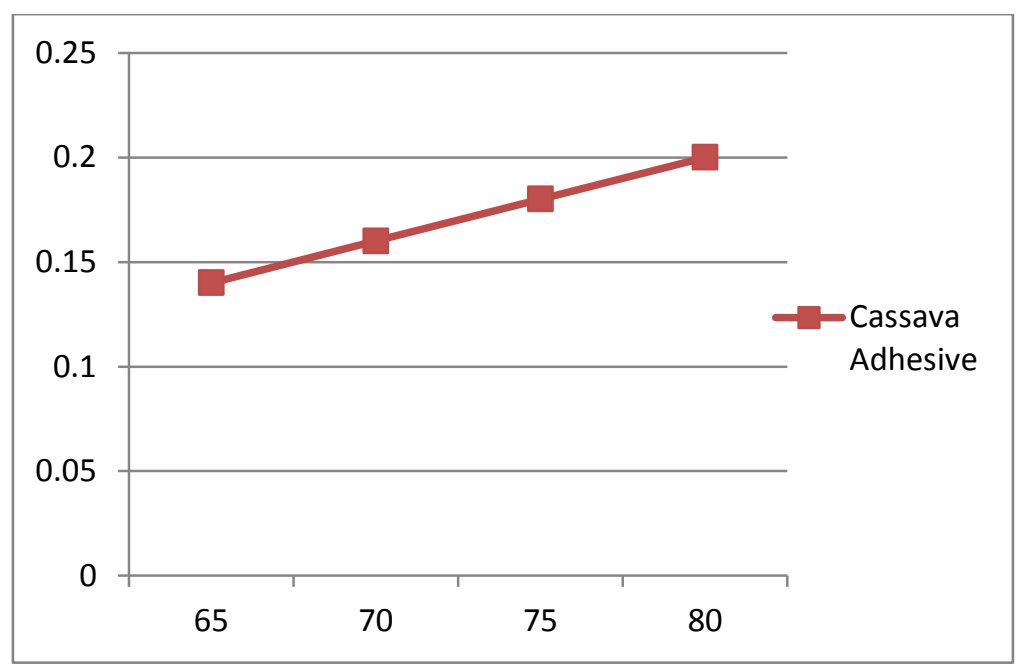

Temperature $\left({ }^{\circ} \mathrm{C}\right)$

Figure 3. Relationship between Temperature and Mass of Borax.

\section{CONCLUSION}

This research work has shown that, the starch and adhesive produced from Cassava roots are of high purity, quality and can compete favourably with the commercial starches/adhesive available in the market. The production of adhesive from cassava starch as a matter of fact, would increase the career opportunities in chemistry education.

The quality assessment of the properties of cassava starch leads to qualitative adhesive. Cassava starch/adhesive could be a good source of cheap and freely available starch, thus saving the industries from spending foreign exchange on importation .In essence; this would also increase employment opportunities and diversify the economic base for farmers that lead to sustainable development in Nigerian. 


\section{Recommendations}

At the end of this research, the following recommendations were made for the reinventing the production of adhesive from cassava starch as a career opportunity in chemistry education.

a) Government should encourage farmers to produce more cassava such as by giving them soft loan etc.

b) Government should provide extention services to the cassava farmers on the modern techniques and methods of cultivation.

c) Government should encourage and set-up small scale industries for production of adhesive for pilot plant that can test the feasibility and marketability of the adhesive.

d) There is need for reorientation and attitudinal change towards entrepreneurial jobs.

e) Therefore, cassava adhesive is recommended for industrial and domestic use and application.

\section{References}

[1] Adeyemo S. A., Journal of Science and Technology Education Research 1 (2010) 1-19.

[2] Akpa J. G., Research Journal in Engineering and Applied Science 1(4) (2012) 214-219.

[3] Aloko D. F., Adebayo G. A., Journal of Engineering and Applied Sciences 2(2) (2007) 440-444.

[4] Angraini V., Sudarmonowati E., Hartati N. S., Visser R. G. F., Starch/starke 61 (2009) $472-481$.

[5] Amine M., Ahmed A., Antonio P., Fatima C., Bertrand C., Maderas ciencia $Y$ Tecnologia 12(3) (2010) 189-197.

[6] Burrell M. M., Journal of Experimental Botany 54(382) (2003) 451-456.

[7] Darkwa N A, Jetuah F. K. Sekyere (2003). Preparation of cassava flour for Production of adhesive for the manufacture of paperboard.

[8] Gracia A. M, Walter M. V. V., Starch/starke 50 (1998) 331-337.

[9] Hoover R., Polymer 45 (2001) 253-267.

[10] Alamu Salawu Abideen, International Letters of Natural Sciences 4 (2013) 26-33. 